\title{
Chemical Characteristics of Native Soil in Shrimp Gher and Agricultural Land
}

\author{
Ashis Kumar Bala ${ }^{1}$, Quazi Hamidul Bari ${ }^{1}$, Amimul Ahsan ${ }^{2 *}$, Moetaz Mahmoud ElSergany ${ }^{3}$, \\ Ravishankar Sathyamurthy ${ }^{4}$, Mohamed Ali Bek ${ }^{5}$, Md Kamal Rowshon ${ }^{6}$, Jayanta Mallick ${ }^{1}$, \\ and Nik Norsyahariati Nik Daud ${ }^{2}$ \\ 1 Dept. of Civil Engineering, Khulna University of Engineering and Technology, Khulna, Bangladesh \\ 2 Dept. of Civil Engg. \& Institute of Advanced Technology, University Putra Malaysia, Serdang, Malaysia \\ 3 e-School of Health and Environmental Studies, Hamdan Bin Mohammed Smart University, Dubai, UAE \\ 4 Dept. of Mechanical Engg., S.A. Engineering College, Chennai, Tamil Nadu, India \\ 5 Dept. Physics \& Engg. Mathematics, Faculty of Engineering, Tanta University, 31734 Tanta, Egypt \\ 6 Dept. of Biological \& Agricultural Engg., University Putra Malaysia, 43400 Serdang, Malaysia \\ *E-mail: amimul@upm.edu.my
}

\begin{abstract}
This study was conducted to characterize the native soil at shrimp Gher and agricultural land in Khulna, Bangladesh, because at present this is a growing concern that the salinity is increasing at an alarming rate. Eight locations were selected and among them five Ghers from south part of Dumuria which is about $60 \mathrm{~km}$ away from KUET campus, Khulna, Bangladesh. In the laboratory, various parameters such as salinity, organic content, chloride, $\mathrm{pH}$, alkalinity, conductivity and moisture content were determined by following standard methods. The chloride and alkalinity were determined manually and $\mathrm{pH}$, conductivity and salinity were determined by digital meter. The organic and moisture content both were highest at $30 \mathrm{~cm}$ depth for both the cases of shrimp Gher and agricultural land. Chloride was highest at $15 \mathrm{~cm}$ depth for both the cases shrimp Gher and agricultural land. Alkalinity was highest at $30 \mathrm{~cm}$ depth for shrimp Gher, however, the lowest was for agricultural land. It is concluded that the salinity and organic content vary with depth, age and soil condition.
\end{abstract}

Keywords: Native soil, salinity, organic content, shrimp gher, Bangladesh.

ENGINEERING JOURNAL Volume 20 Issue 2

Received 20 April 2015

Accepted 5 August 2015

Published 18 May 2016

Online at http://www.engj.org

DOI: $10.4186 /$ ej.2016.20.2.1 


\section{Introduction}

The world largest mangrove forest, Sundarbans is situated at the south-western coastal zone of Bangladesh that covers about $40 \%$ of the total forest and gives good feedback to the national economy. From last few years, it has been said that salinity is increasing drastically in this particular region of Bangladesh due to sea water intrusion, reduction of fresh water flow and human activities like shrimp farming. Details of shrimp farming in southwest (Khulna division) Bangladesh are reported [1-4]. Effects of shrimp aquaculture industry (in coastal Bangladesh) on ecology and economic development are studied [5-9]. Salinity, sanitary hygiene and organic contents may affect the shrimp production [10-12]. Management of shrimp aquaculture and coastal/nearshore fisheries are investigated [13-15]. Gher is a coastal shrimp aquaculture in a field or pond situated by the side of a river. People cultivate rice in winter at Gher and shrimp in summer [14]. An integrated management approach for shrimp culture development is proposed [16]. Standard seawater comparisons are updated [17]. Socio-economic impacts of shrimp and crab aquaculture are reported [18-21].

This study is carried out to determine the present condition about salinity and organic content of west part of Khulna, Bangladesh. Soil salinity is the salt content in the soil. Salt is a natural element of soils and water. The ions responsible for salinization are: $\mathrm{Na}^{+}, \mathrm{K}^{+}, \mathrm{Ca}^{2+}, \mathrm{Mg}+$ and $\mathrm{Cl}$. About 10.2 lakh hectare of land is now salinity contaminated in 19 districts according to a study by the Bangladesh Soil Resources Development Institute. It has caused crisis of drinking water [10].

When plant/debris is added to soil, it is broken down by microbes. The American Society for Testing and Materials (ASTM) stated an approach for classifying soils having organic contents. Electrical conductivity (EC) is a measure of soil conductance where a current travels.

Alkaline soil defined as the soils with $\mathrm{pH}$ greater than 7.3. Soil alkalinity is a naturally occurring phenomenon that can be escalated by human activity. Water content is the quantity of water contained in a mineral on a volumetric basis. The ideal range of $\mathrm{pH}$ in soil is 6.0 to 6.5 because most of the plants' nutrients are available in this stage [22]. The total organic carbon (TOC) is the amount of organic matter in soils. This variation occurs due to soil formation and geologic condition of that particular area. During the soil formation, heavy metals moves downwards and the organic matter moves up due to their light weight and composition of organic soils.

Both saline and fresh water can be used for this cultivation [5]. Currently, Bangladesh produces more than $2.5 \%$ of the global production of shrimp and becomes the $7^{\text {th }}$ largest exporter of shrimp [2]. Fisheries sector contributes $4.57 \%$ to the Gross Domestic Product (GDP) in Bangladesh and shrimp alone contributes about $0.07 \%$ of total export income [6]. In 2009-2010, Bangladesh earned about Taka 45000 million by exporting shrimp [21]. Rearing of fish along with paddy is an age-old practice in Bengal. Use of pesticide in recent years, however, has greatly impeded fish culture in paddy fields [3].

Apart from the overall contribution of shrimp cultivation to the national economy of Bangladesh, it has been causing severe threats to local ecological systems, such as deterioration of soil and water quality, depletion of mangrove forest, decrease of local variety of rice and fish, saline water intrusion in ground water, local water pollution and change of local hydrology [9]. The Environmental Justice Foundation (EJF) documented the case of women who walk further and long distances to carry drinking water due to increase of salinity in nearer water sources (e.g. tube well and well) as a result of shrimp culture [23]. Water quality and partial mass budget in extensive shrimp ponds are studied [24].

In this study, the native soil is characterized in terms of organic content and salinity collected. Eight locations were selected and among them five Ghers from south part of Dumuria which is about $60 \mathrm{~km}$ away from KUET campus and another three from west part of Teligati (near Khulna bypass road) which is about $4 \mathrm{~km}$ away from KUET campus (Khulna, Bangladesh). In each Gher, three points were selected and from each point, two soil samples were collected at the depth of 15 and $30 \mathrm{~cm}$ from the existing ground surface. In the laboratory, through standard methods various parameters such as salinity, organic content, chloride, $\mathrm{pH}$, alkalinity, conductivity and moisture content were determined.

\section{Methodology}

It is very essential to determine the amount of salinity and organic content in shrimp Gher and Agricultural Land. Because due to sea water intrusion, reduction of fresh water flow and human activities like shrimp 
farming, salinity is increasing in south part of Khulna day by day. In the laboratory, the salinity test was performed on the collected soil sample to determine the amount salinity.

Laboratory Investigation: In 2013, the soil samples were collected from eight places among them four were shrimp Gher, two were combined of shrimp Gher and Agricultural land and another two were Agricultural land. The five soil samples were collected from Dumuria and three from Teligati. After the collection of soil samples from the selected locations, the samples were prepared for the desired test in the laboratory. According to standard methods, various parameters were tested and hence discussed in the following sections.

Sample Preparation: First the beaker was cleaned properly and dried. $100 \mathrm{gm}$ soil was taken in the beaker. $100 \mathrm{ml}$ water was added to the soil sample. Then soil and water were mixed properly with glass rod. After that the mixture was kept in static condition about half an hour. The funnel was placed with stand rod. The filter paper was folded and made cone shaped then placed into funnel. The mixture was slightly added into funnels and observed that the filtration rate was initially high. Finally filtered water for respective sample was obtained.

$p H$, Conductivity and Salinity: Apparatus were Hack meter and graduated cylinder. The filter water was placed into the graduated cylinders. The $\mathrm{pH}$ meter was immersed into the graduated cylinders such that at least 2 inch of $\mathrm{pH}$ tube was dipped. After that the reading was taken.

Alkalinity: $100 \mathrm{ml}$ graduated cylinder was taken. $90 \mathrm{ml}$ distilled water was mixed with $10 \mathrm{ml}$ of 0.02 normality $\mathrm{H}_{2} \mathrm{SO}_{4}$ and the overall system is shown in Fig. 1.

Calculation of Alkalinity:

Alkalinity $=[\{($ FR-IR $)-0.3\} \times 500 \times$ Dilution Factor $] /$ Sample used

Dilution Factor $=($ Sample used + Distilled water $) /$ Sample used

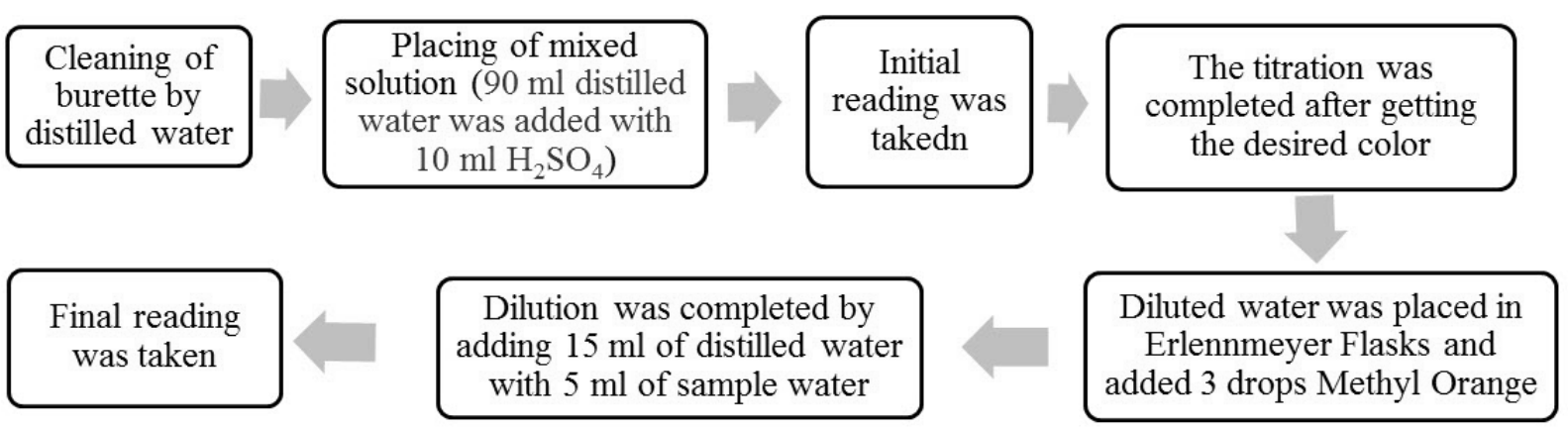

Fig. 1. Schematic diagram on the method of determining alkalinity in different places.

Chloride: $100 \mathrm{ml}$ graduated cylinder was taken. $15 \mathrm{ml}$ distilled water was mixed with $5 \mathrm{ml}$ sample water and the overall system is shown in Fig. 2.

Calculation of Chloride:

Chloride $=[\{($ FR-IR $)-0.3\} \times 500 \times$ Dilution Factor $] /$ Sample used

Dilution Factor $=($ Sample used + Distilled water $) /$ Sample used

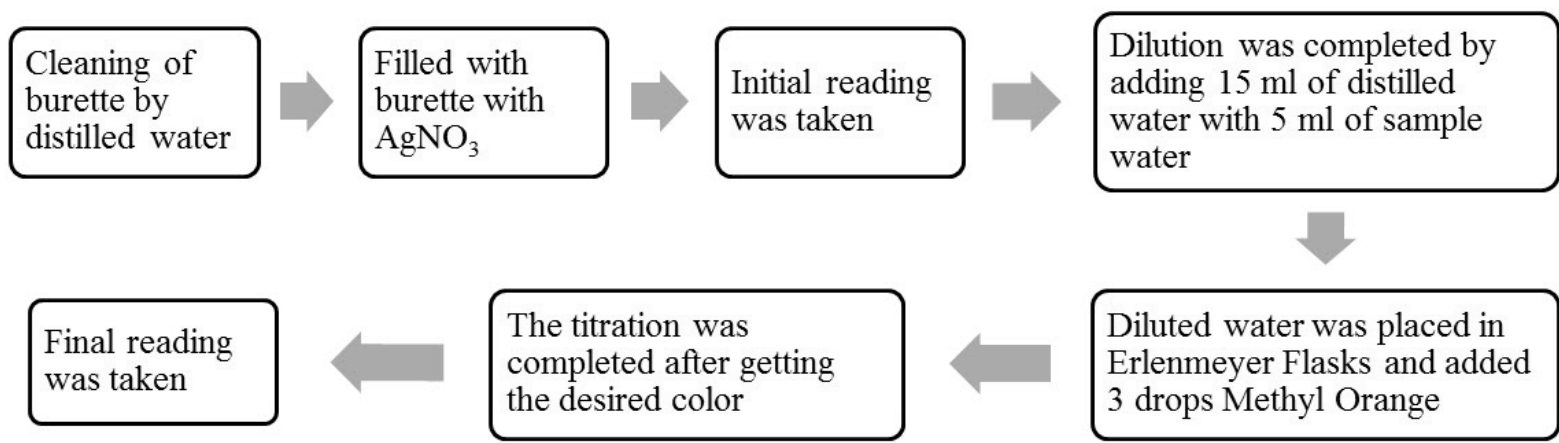

Fig. 2. Schematic diagrams on the method of determining organic content in different places.

Moisture Content: Some amount of soil sample was measured. Then the sample was kept in oven at $105^{\circ} \mathrm{C}$. Duration of heating was 24 hours. 


\section{Calculation of moisture content.}

$$
\mathrm{MC}(\%)=\left\{\left(\mathrm{W}_{\mathrm{w}}-\mathrm{W}_{\mathrm{d}}\right) / \mathrm{W}_{\mathrm{w}}\right\} \times 100
$$

where $\mathrm{W}_{\mathrm{w}}=$ Total wet weight of the soil sample, and $\mathrm{W}_{\mathrm{d}}=\mathrm{Weight}$ after burning at $105^{\circ} \mathrm{C}$.

Organic Content: Three techniques exist to determine organic content, such as loss on ignition, oxidation with $\mathrm{H}_{2} \mathrm{O}_{2}$, and dichromate oxidation. In this study, loss on ignition method was used. The oven dried sample was crumbled into powder. Some amount of powdered sample was weighted and kept in muffle furnace at $550^{\circ} \mathrm{C}$ temperature for 4.5 hours. Then the sample was released from muffle furnace and weighted again. The amount of organic content was determined by following formula.

$$
\mathrm{OC}(\%)=\left\{\left(\mathrm{W}_{\mathrm{t}}-\mathrm{W}_{\mathrm{b}}\right) / \mathrm{W}_{\mathrm{t}}\right\} \times 100
$$

where $\mathrm{W}_{\mathrm{t}}=$ Total dry weight of the soil sample, and $\mathrm{W}_{\mathrm{b}}=$ Weight after burning at $550^{\circ} \mathrm{C}$.

\section{Results and Discussion}

Important chemical parameters of soil samples collected from the different locations are monitored to achieve the desired goal and are shown in Tables 1-4. It is compared between Gher A and Gher B to show the soil properties of Gher with and without agricultural uses.

Table 1. Chemical parameters of native soil in Gher A and Combined Agricultural Land and Shrimp

\begin{tabular}{|c|c|c|c|c|c|c|c|}
\hline \multirow{2}{*}{ Parameters } & \multicolumn{7}{|c|}{ Gher-A } \\
\hline & AX1 & AY1 & AX2 & AY2 & AX3 & AY3 & Avg. \\
\hline E. Conductivity (ms/cm) & 41.5 & 26 & 35.5 & 44 & 90.5 & 33.9 & 45.23 \\
\hline Salinity $(\mathrm{gm} / \mathrm{L})$ & 26.6 & 15.9 & 22.1 & 28.4 & 31.8 & 21.3 & 24.35 \\
\hline Chloride $(\mathrm{mg} / \mathrm{L})$ & 430 & 360 & 460 & 610 & 400 & 490 & 458.33 \\
\hline Alkalinity as $\mathrm{MgCO}_{3}(\mathrm{mg} / \mathrm{L})$ & 260 & 360 & 160 & 380 & 320 & 420 & 316.67 \\
\hline Organic Content $(\%)$ & 2.97 & 4.4 & 4.14 & 6.36 & 4.03 & 4.98 & 4.48 \\
\hline Moisture Content (\%) & 40.5 & 38.7 & 50.10 & 61.77 & 30.2 & 35.37 & 42.77 \\
\hline $\mathrm{pH}$ & 7.99 & 8.08 & 7.84 & 7.02 & 7.94 & 8.18 & 7.84 \\
\hline Chloride (mg/gm) & 1.02 & 0.81 & 1.38 & 2.58 & 0.75 & 1.03 & 1.26 \\
\hline \multirow{2}{*}{ Parameters } & \multicolumn{7}{|c|}{ Combined Agricultural Land and Shrimp Gher-B } \\
\hline & BX1 & BY1 & BX2 & BY2 & BX3 & BY3 & Avg. \\
\hline E. Conductivity $(\mathrm{ms} / \mathrm{cm})$ & 20 & 21.6 & 25 & 24.7 & 25 & 77.7 & 32.33 \\
\hline Salinity $(\mathrm{gm} / \mathrm{L})$ & 11.9 & 12.9 & 15.6 & 14.8 & 15.2 & 11.4 & 13.63 \\
\hline Chloride $(\mathrm{mg} / \mathrm{L})$ & 300 & 330 & 330 & 410 & 380 & 420 & 361.67 \\
\hline Alkalinity as $\mathrm{MgCO}_{3}(\mathrm{mg} / \mathrm{L})$ & 380 & 340 & 420 & 320 & 400 & 520 & 396.67 \\
\hline Organic Content (\%) & 4.04 & 5.99 & 3.97 & 4.5 & 4.11 & 5.44 & 4.68 \\
\hline Moisture Content (\%) & 34.7 & 44.8 & 45.66 & 47.02 & 48.48 & 38.2 & 43.14 \\
\hline $\mathrm{pH}$ & 8.17 & 7.82 & 8.05 & 7.33 & 7.95 & 8.27 & 7.93 \\
\hline Chloride (mg/gm) & 0.62 & 0.87 & 0.88 & 1.14 & 1.1 & 0.94 & 0.93 \\
\hline
\end{tabular}
Gher-B.

Gher- $A$ is 20 years old Shrimp Gher, Combined Agricultural land and Shrimp Gher-B is 8 years old; X=Sample at $15 \mathrm{~cm}$ depth; $Y=$ Sample at $30 \mathrm{~cm}$ depth; Avg.=Average.

Table 2. Chemical parameters of native soil in Gher C and Gher D.

\begin{tabular}{lccccccc}
\hline \multirow{2}{*}{ Parameters } & \multicolumn{9}{c}{ Gher-C } & \multicolumn{1}{c}{} \\
\cline { 2 - 8 } & CX1 & CY1 & CX2 & CY2 & CX3 & CY3 & Avg. \\
\hline E. Conductivity (ms/cm) & 22.3 & 34.9 & 19.78 & 19.03 & 21.7 & 22.9 & 23.44 \\
Salinity (gm/L) & 13.4 & 22 & 11.8 & 11.3 & 13 & 13.8 & 14.22 \\
Chloride (mg/L) & 420 & 590 & 360 & 310 & 330 & 340 & 391.67 \\
Alkalinity as MgCO 3 (mg/L) & 240 & 200 & 240 & 420 & 540 & 240 & 313.33 \\
Organic Content (\%) & 4.91 & 5.34 & 4.73 & 4.02 & 5.02 & 3 & 4.50 \\
Moisture Content (\%) & 31.2 & 30.17 & 33.56 & 30.77 & 29.52 & 27.47 & 30.45 \\
pH & 7.7 & 7.95 & 7.85 & 7.92 & 7.69 & 8.4 & 7.92 \\
Chloride (mg/gm) & 0.8 & 1.01 & 0.72 & 0.59 & 0.61 & 0.60 & 0.72 \\
\hline
\end{tabular}




\begin{tabular}{lccccccc}
\hline \multirow{2}{*}{ Parameters } & \multicolumn{9}{c}{ Gher-D } & & \\
\cline { 2 - 8 } & DX1 & DY1 & DX2 & DY2 & DX3 & DY3 & Avg. \\
\hline E. Conductivity (ms/cm) & 22.4 & 43.8 & 25.6 & 38.7 & 21.9 & 40.5 & 32.15 \\
Salinity (gm/L) & 13.5 & 28.3 & 15.6 & 24.6 & 13.7 & 25.9 & 20.27 \\
Chloride (mg/L) & 320 & 750 & 460 & 580 & 350 & 680 & 523.33 \\
Alkalinity as MgCO, 3 (mg/L) & 200 & 220 & 200 & 220 & 200 & 240 & 213.33 \\
Organic Content (\%) & 6.4 & 5.64 & 5.31 & 5.47 & 6.59 & 6.13 & 5.92 \\
Moisture Content (\%) & 36.2 & 29.72 & 37.29 & 31.66 & 37.35 & 30.17 & 33.73 \\
pH & 8.36 & 8.41 & 7.9 & 8.17 & 8.45 & 8.47 & 8.29 \\
Chloride (mg/gm) & 0.68 & 1.38 & 1.00 & 1.12 & 0.77 & 1.27 & 1.04 \\
\hline
\end{tabular}

Shrimp Gher-C is 5 years old at Dumuria, Shrimp Gher-D is 13 years old at Dumuria; $X=$ Sample at $15 \mathrm{~cm}$ depth; $Y=$ Sample at $30 \mathrm{~cm}$ depth; Avg. $=$ Average.

Table 3. Chemical parameters of native soil in Agricultural Land E and Combined Agricultural Land and Shrimp Gher-F.

\begin{tabular}{|c|c|c|c|c|c|c|c|}
\hline \multirow{2}{*}{ Parameters } & \multicolumn{7}{|c|}{ Agricultural Land -E } \\
\hline & EX1 & EY1 & EX2 & EY2 & EX3 & EY3 & Avg. \\
\hline E. Conductivity $(\mathrm{ms} / \mathrm{cm})$ & 17.16 & 36.7 & 25.3 & 41.4 & 17.24 & 38 & 29.30 \\
\hline Salinity $(\mathrm{gm} / \mathrm{L})$ & 10.1 & 22.8 & 15.4 & 26.5 & 10.7 & 24.1 & 18.27 \\
\hline Chloride (mg/L) & 310 & 620 & 430 & 810 & 630 & 730 & 588.33 \\
\hline Alkalinity as $\mathrm{MgCO}_{3}(\mathrm{mg} / \mathrm{L})$ & 180 & 220 & 140 & 120 & 160 & 160 & 163.33 \\
\hline Organic Content $(\%)$ & 5.0 & 3.89 & 5.2 & 4.74 & 5.15 & 3.29 & 4.55 \\
\hline Moisture Content (\%) & 33.29 & 24.4 & 37.78 & 30.72 & 38.51 & 24.19 & 31.48 \\
\hline $\mathrm{pH}$ & 8.16 & 8.63 & 8.12 & 8.16 & 8.29 & 8.65 & 8.34 \\
\hline Chloride (mg/gm) & 0.62 & 1.02 & 0.95 & 1.53 & 1.42 & 1.20 & 1.12 \\
\hline \multirow{2}{*}{ Parameters } & \multicolumn{7}{|c|}{ Combined Agricultural Land and Shrimp Gher-F } \\
\hline & FX1 & FY1 & FX2 & FY2 & FX3 & FY3 & Avg. \\
\hline E. Conductivity $(\mathrm{ms} / \mathrm{cm})$ & 6.62 & 6.88 & 6.13 & 6.02 & 8.90 & 11.23 & 7.63 \\
\hline Salinity $(\mathrm{gm} / \mathrm{L})$ & 3.60 & 3.80 & 3.30 & 3.30 & 5.0 & 6.40 & 4.23 \\
\hline Chloride (mg/L) & 420 & 590 & 360 & 310 & 330 & 340 & 391.67 \\
\hline Alkalinity as $\mathrm{MgCO}_{3}(\mathrm{mg} / \mathrm{L})$ & 240 & 200 & 240 & 420 & 540 & 240 & 313.33 \\
\hline Organic Content $(\%)$ & 6.51 & 7.51 & 7.08 & 7.50 & 6.70 & 6.45 & 6.96 \\
\hline Moisture Content (\%) & 29.20 & 33.47 & 32.15 & 30.70 & 36.40 & 28.75 & 31.78 \\
\hline $\mathrm{pH}$ & 7.94 & 7.83 & 7.68 & 7.90 & 7.25 & 7.83 & 7.74 \\
\hline Chloride (mg/gm) & 0.77 & 1.18 & 0.70 & 0.58 & 0.71 & 0.61 & 0.76 \\
\hline
\end{tabular}

Agricultural Land -E is at Dumuria, Combined Agricultural Land and Shrimp Gher-F is 10 years old at Teligati; $X=$ Sample at $15 \mathrm{~cm}$ depth; $Y=$ Sample at $30 \mathrm{~cm}$ depth; Avg. = Average.

Table 4. Chemical parameters of native soil in Gher G and Agricultural Land H.

\begin{tabular}{|c|c|c|c|c|c|c|c|}
\hline \multirow{2}{*}{ Parameters } & \multicolumn{7}{|c|}{ Gher-G } \\
\hline & GX1 & GY1 & GX2 & GY2 & GX3 & GY3 & Avg. \\
\hline E. Conductivity $(\mathrm{ms} / \mathrm{cm})$ & 7.23 & 7.51 & 7.02 & 7.19 & 7.65 & 8.05 & 7.44 \\
\hline Salinity $(\mathrm{gm} / \mathrm{L})$ & 4.2 & 4.35 & 3.90 & 4.09 & 5.05 & 5.45 & 4.51 \\
\hline Chloride (mg/L) & 390 & 450 & 420 & 390 & 435 & 500 & 430.83 \\
\hline Alkalinity as $\mathrm{MgCO}_{3}(\mathrm{mg} / \mathrm{L})$ & 412 & 320 & 230 & 215 & 490 & 320 & 331.17 \\
\hline Organic Content $(\%)$ & 7.67 & 8.86 & 6.77 & 7.85 & 7.89 & 8.85 & 7.98 \\
\hline Moisture Content (\%) & 33.83 & 37.7 & 35.2 & 25.67 & 39.65 & 39.2 & 35.21 \\
\hline $\mathrm{pH}$ & 7.82 & 8.06 & 7.59 & 7.95 & 7.89 & 8.12 & 7.91 \\
\hline Chloride (mg/gm) & 0.79 & 0.99 & 0.88 & 0.66 & 1.01 & 1.14 & 0.91 \\
\hline \multirow{2}{*}{ Parameters } & \multicolumn{7}{|c|}{ Agricultural Land-H } \\
\hline & HX1 & HY1 & HX2 & HY2 & HX3 & HY3 & Avg. \\
\hline E. Conductivity $(\mathrm{ms} / \mathrm{cm})$ & 7.66 & 0.024 & 6.11 & 5.07 & 0.0185 & 0.0175 & 3.15 \\
\hline Salinity $(\mathrm{gm} / \mathrm{L})$ & 4.20 & 0 & 3.3 & 2.7 & 0 & 0 & 1.70 \\
\hline Chloride $(\mathrm{mg} / \mathrm{L})$ & 140 & 120 & 210 & 140 & 180 & 190 & 163.33 \\
\hline Alkalinity as $\mathrm{MgCO}_{3}(\mathrm{mg} / \mathrm{L})$ & 755 & 4000 & 2420 & 2500 & 1940 & 1640 & 2209.17 \\
\hline Organic Content $(\%)$ & 12.73 & 12.73 & 12.92 & 12.40 & 13 & 12.94 & 12.79 \\
\hline Moisture Content (\%) & 42.69 & 36.89 & 40.96 & 36.45 & 50.73 & 43.56 & 41.88 \\
\hline $\mathrm{pH}$ & 7.94 & 7.83 & 7.68 & 7.9 & 7.25 & 7.83 & 7.74 \\
\hline Chloride (mg/gm) & 0.35 & 0.26 & 0.50 & 0.30 & 0.55 & 0.48 & 0.407 \\
\hline
\end{tabular}

Shrimp Gher-G is 8 years old at Teligati, Agricultural Land-H is at Teligati; $X=S$ ample at $15 \mathrm{~cm}$ depth; $Y=S$ ample at $30 \mathrm{~cm}$ depth; Avg. $=$ Average. 
Since salinity and organic content are the basic and most important parameters of soil, so these are discussed in details here. Figure 3 shows the salinity is higher at $15 \mathrm{~cm}$ depth than $30 \mathrm{~cm}$ depth. Similarly in Fig. 4, the value of salinity is higher at $30 \mathrm{~cm}$ depth than $15 \mathrm{~cm}$ depth. The variation of organic content of the collected soil samples with the increase of depth as shown in Figs. 5 and 6. Figure 5 depicts that the organic content in case of old Gher was found higher at $30 \mathrm{~cm}$ depth than as that of $15 \mathrm{~cm}$ depth. Similarly in Fig. 6, the value of Organic content is also higher at $30 \mathrm{~cm}$ depth than $15 \mathrm{~cm}$ depth. Gher-A is 20 years old and B is combined agricultural land and Shrimp Gher.

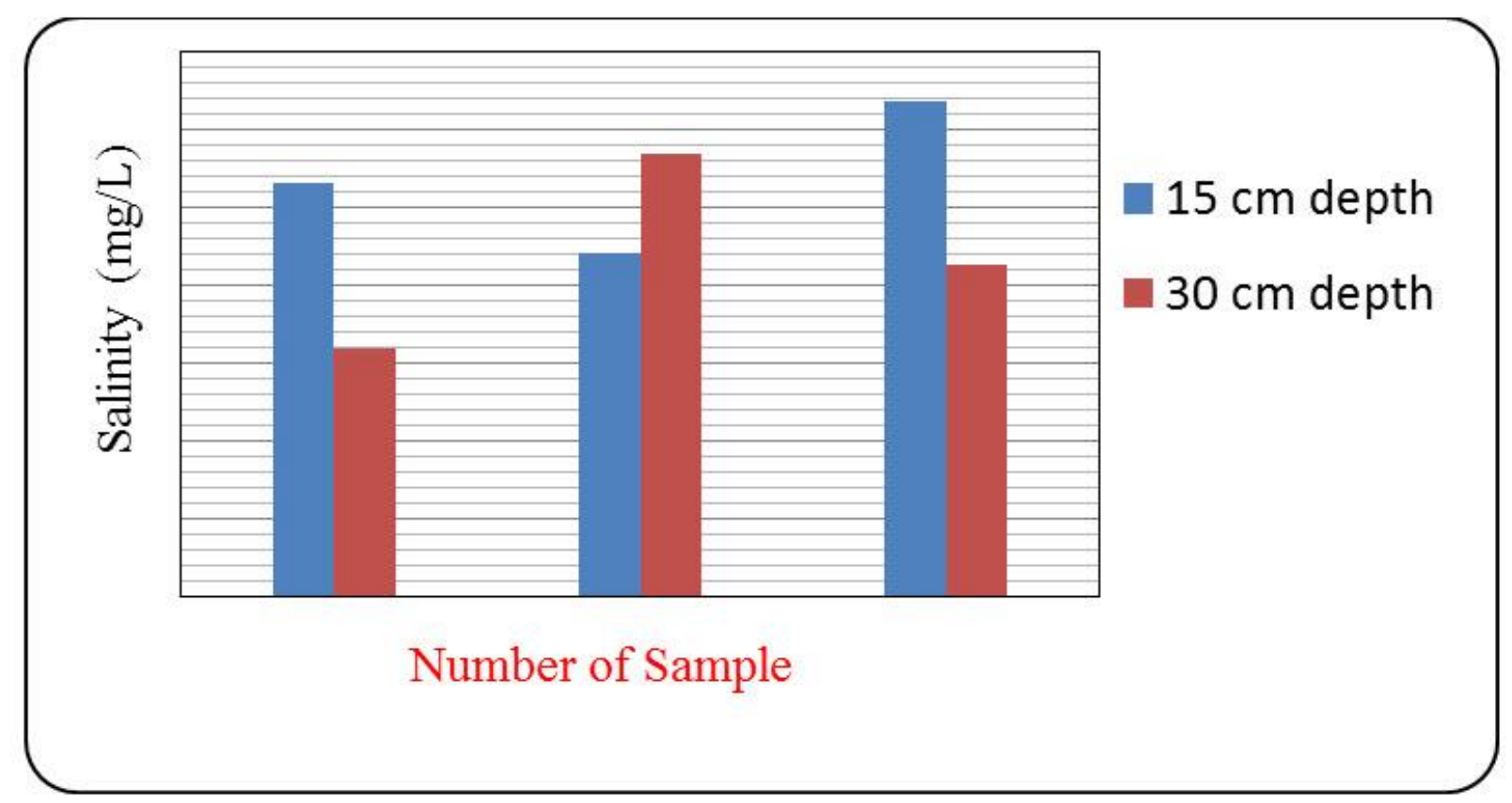

Fig. 3. Variation of Salinity with depth of soil for Gher-A.

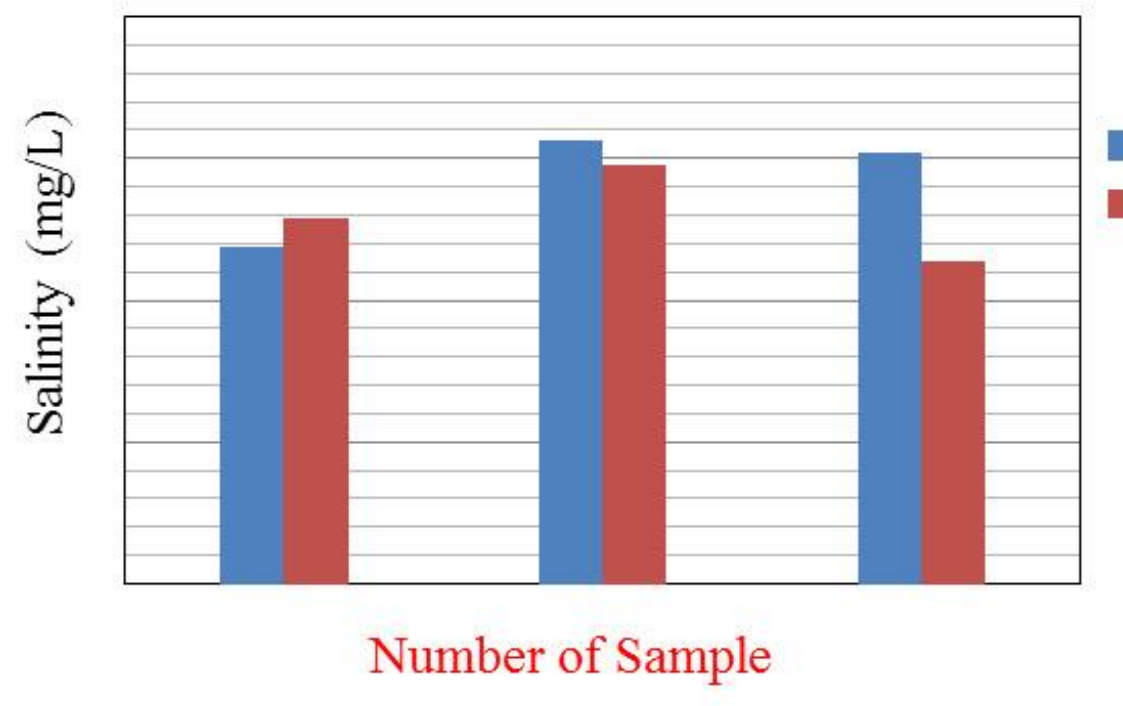

Fig. 4. Variation of Salinity with depth of soil for Gher-B. 


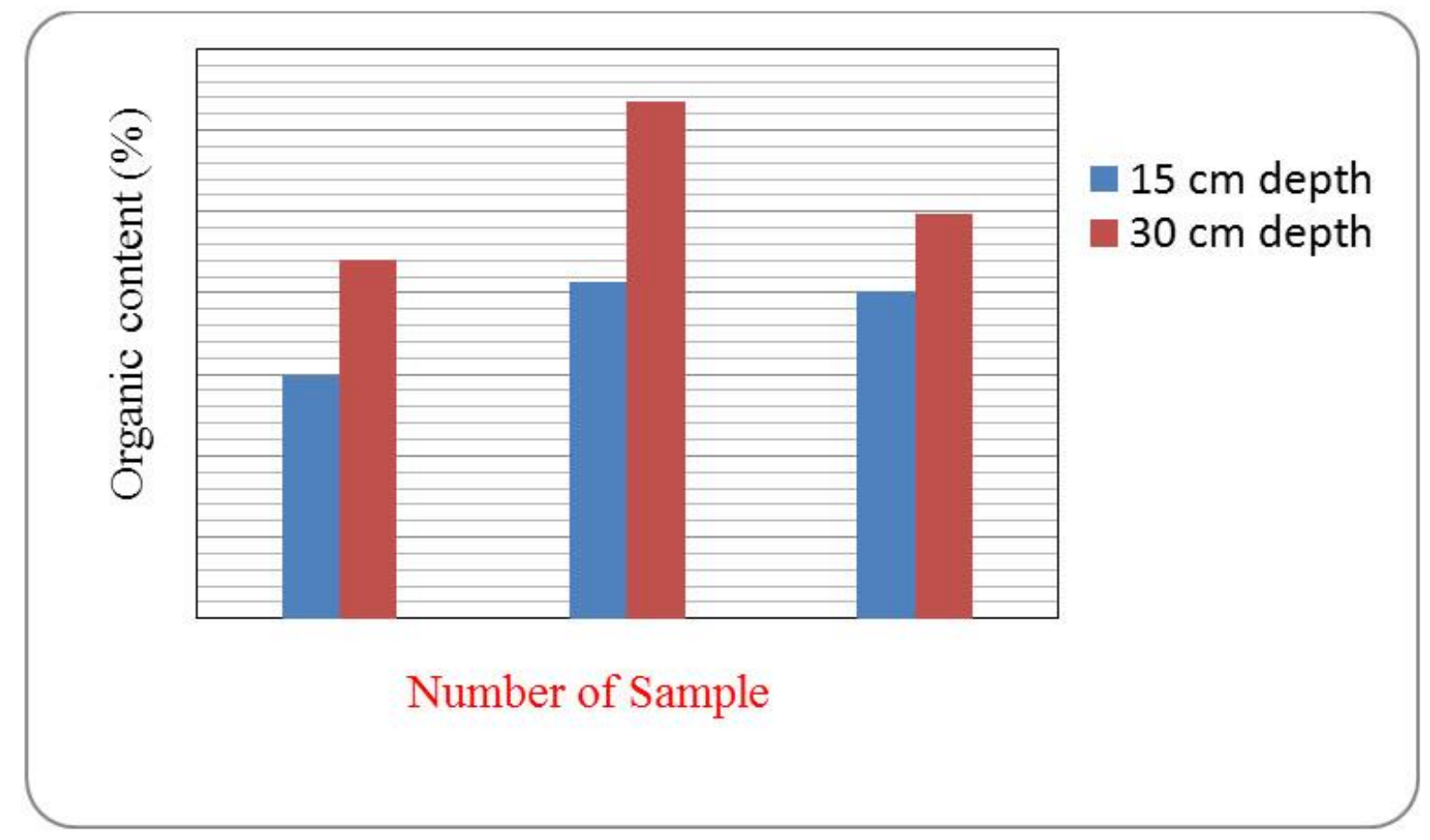

Fig. 5. Variation of Organic content with depth of soil for Gher-A.

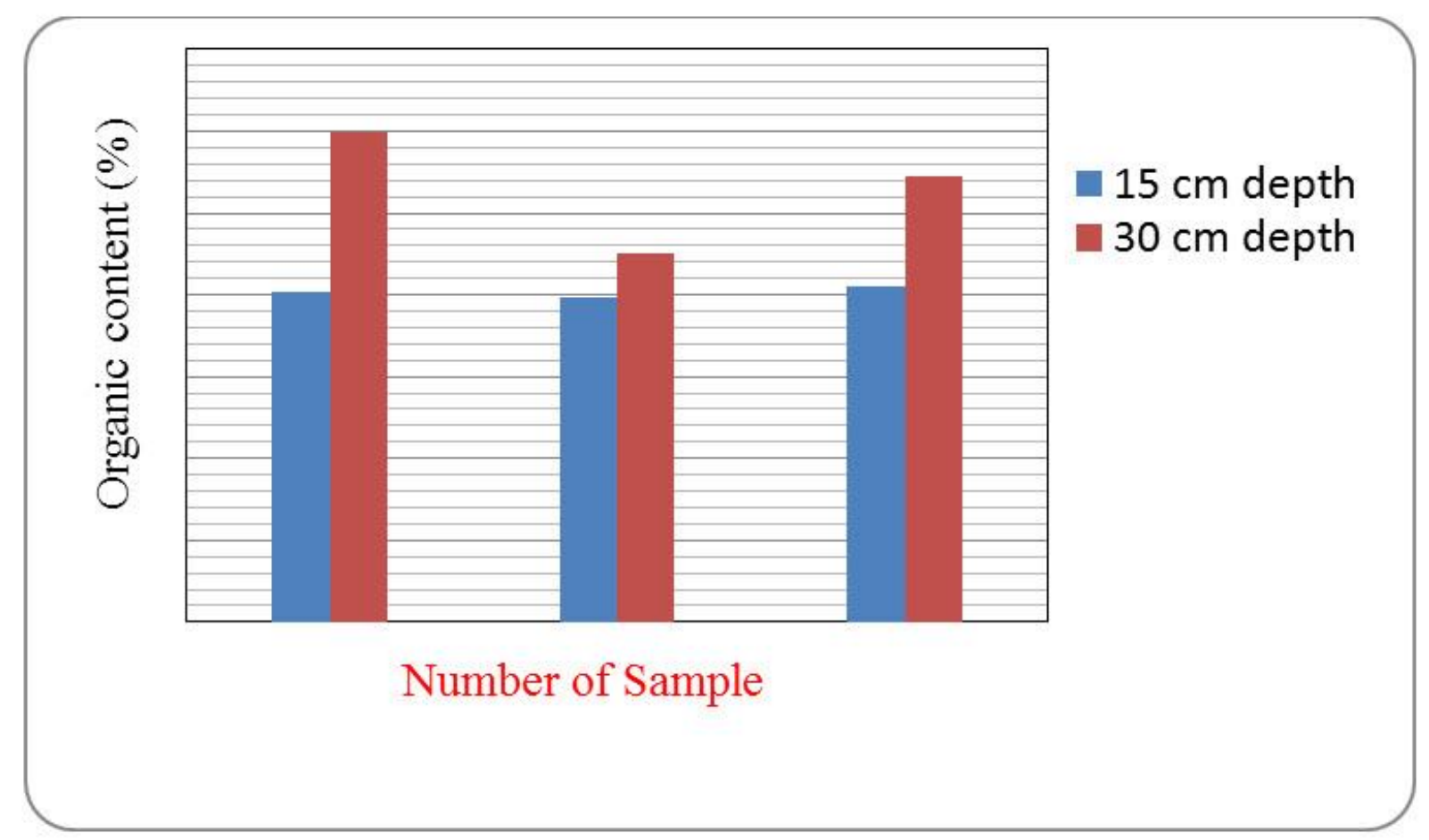

Fig. 6. Variation of Organic content with depth of soil for Gher-B. 


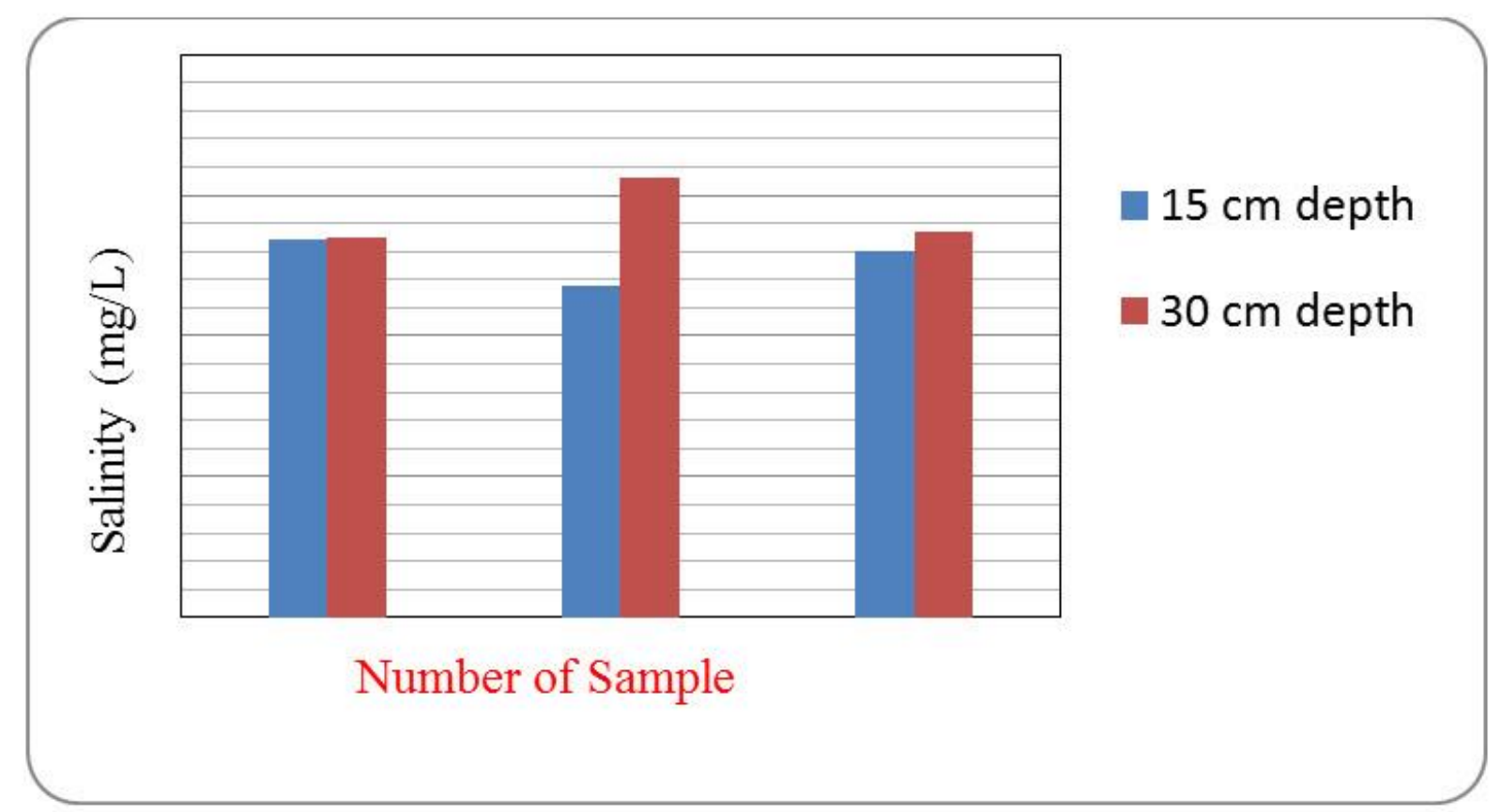

Fig. 7. Variation of Salinity with depth of soil for Gher-C.

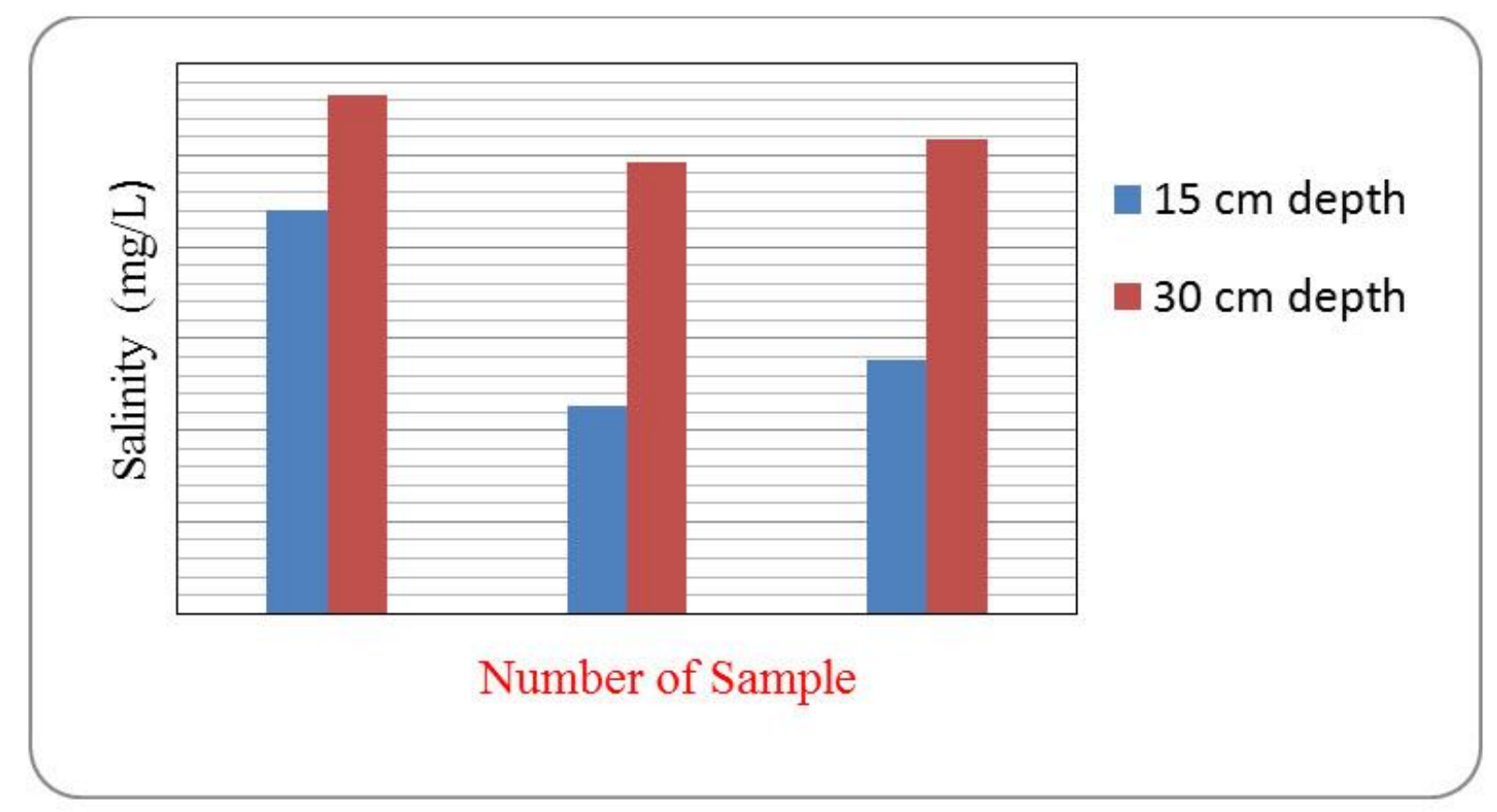

Fig. 8. Variation of Salinity with depth of soil for Gher-D.

Figure 7 shows the salinity is higher at $30 \mathrm{~cm}$ depth than $15 \mathrm{~cm}$ depth for Gher C. Similarly for Gher D in Fig. 8, the value of salinity is higher at $30 \mathrm{~cm}$ depth than $15 \mathrm{~cm}$ depth. Figure 9 depicts that the organic content in case of shrimp Gher was found higher at $15 \mathrm{~cm}$ depth than as that of $30 \mathrm{~cm}$ depth. Similarly in Fig. 10, the value of organic content is also higher at $15 \mathrm{~cm}$ depth than $30 \mathrm{~cm}$ depth. Gher-C is 5 years old and Gher D is 13 years old Shrimp Gher. 


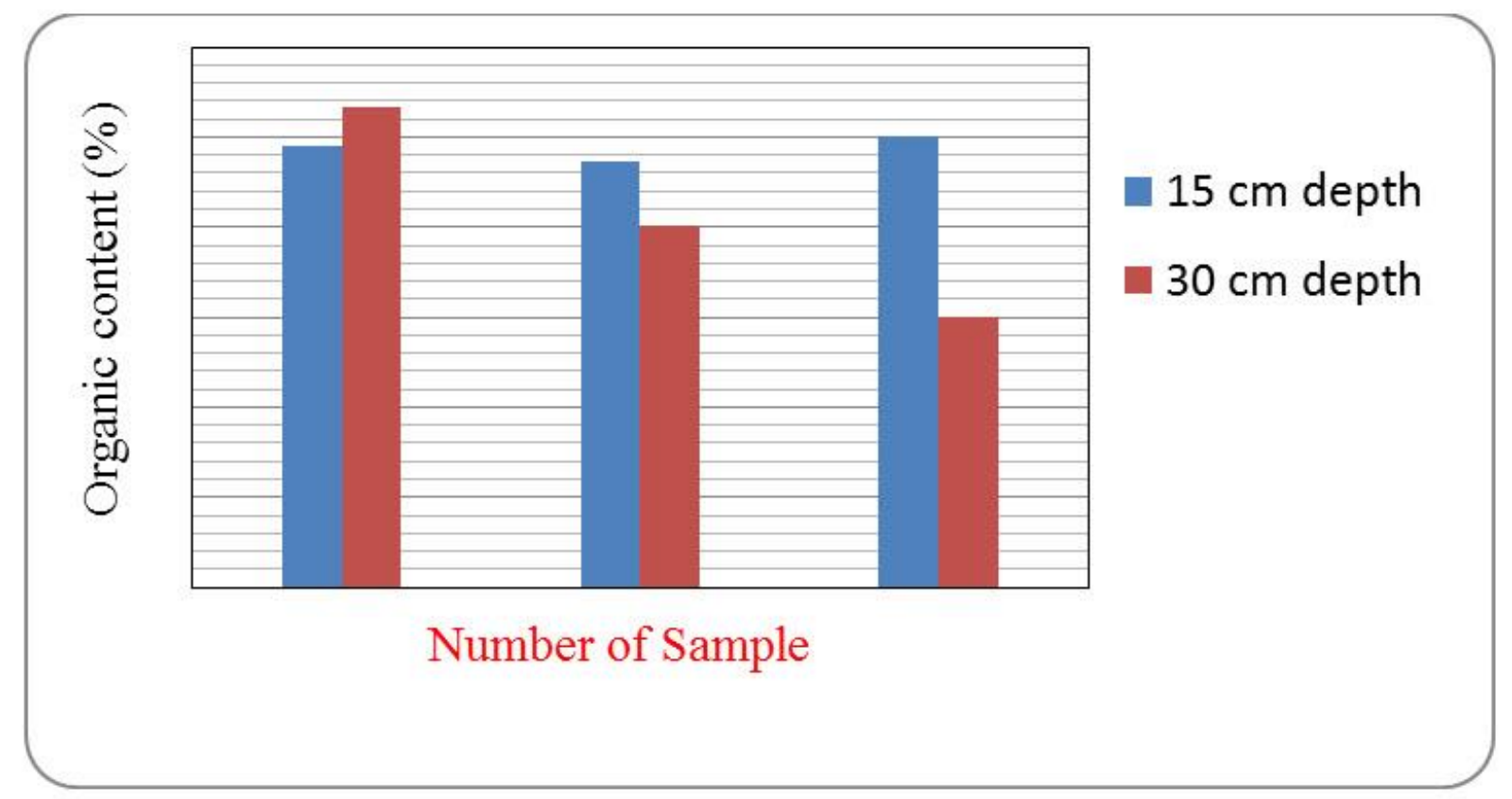

Fig. 9. Variation of Organic content with depth of soil for Gher-C.

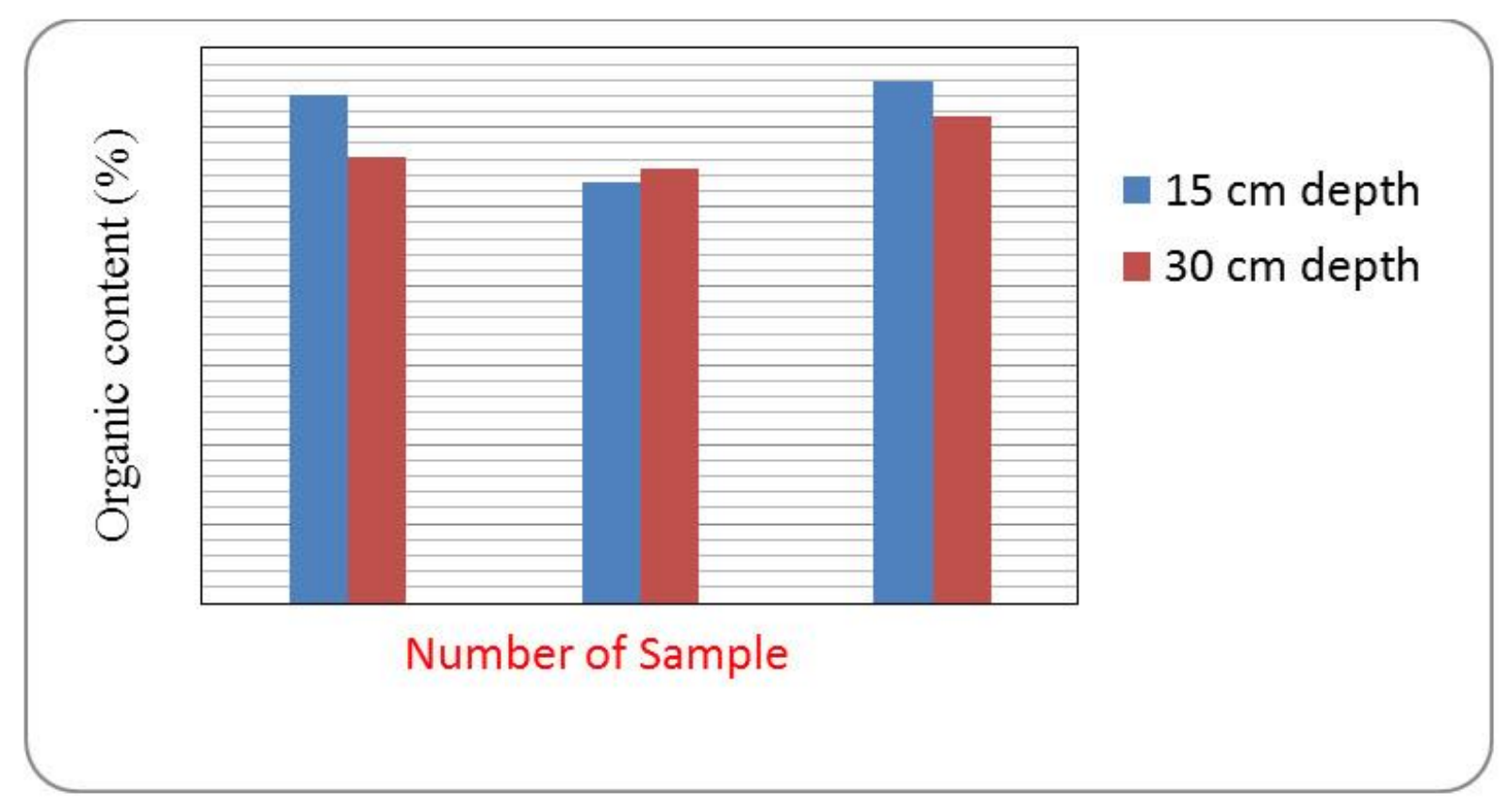

Fig. 10. Variation of Organic content with depth of soil for Gher-D. 


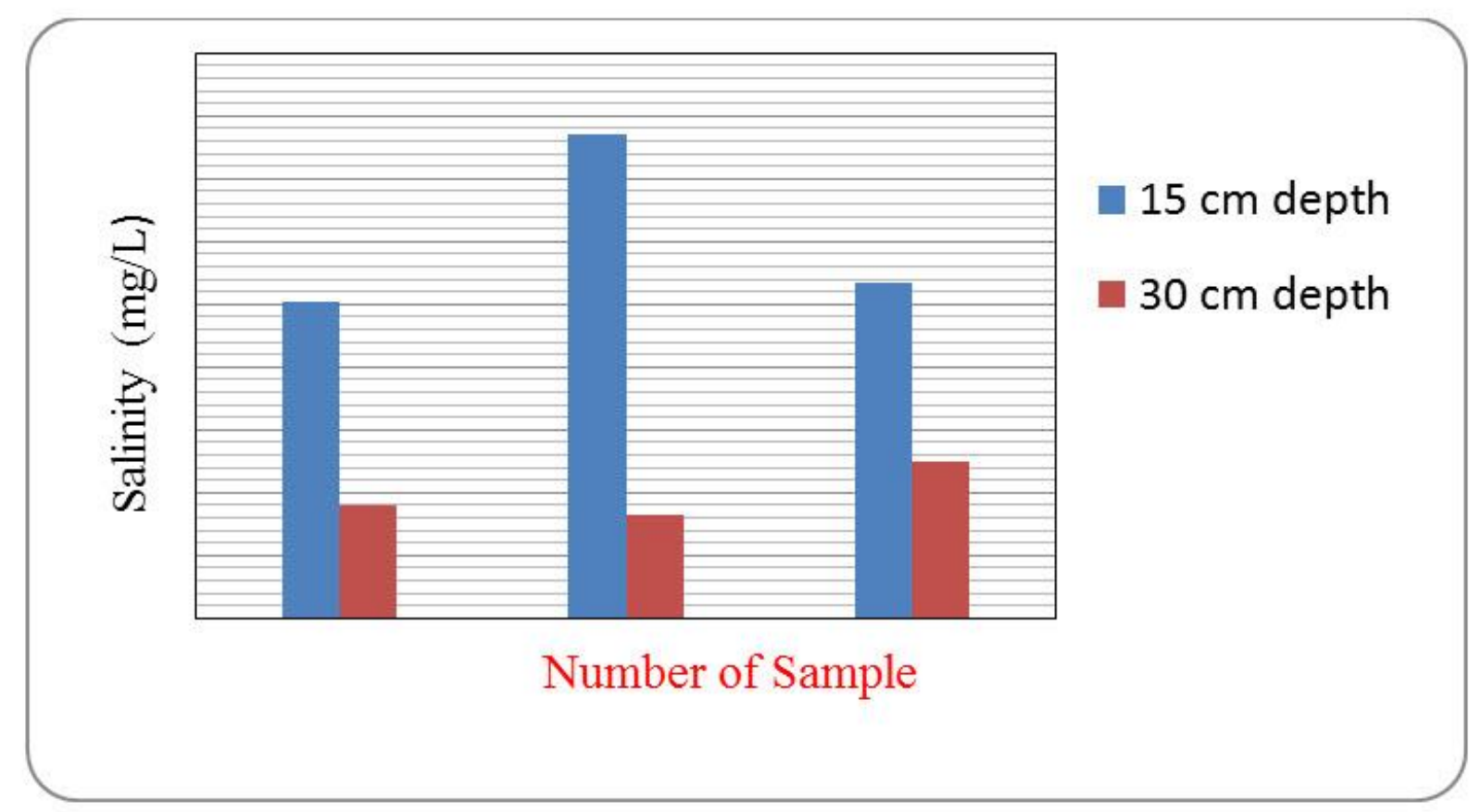

Fig. 11. Variation of Salinity with depth of soil for Gher-E.

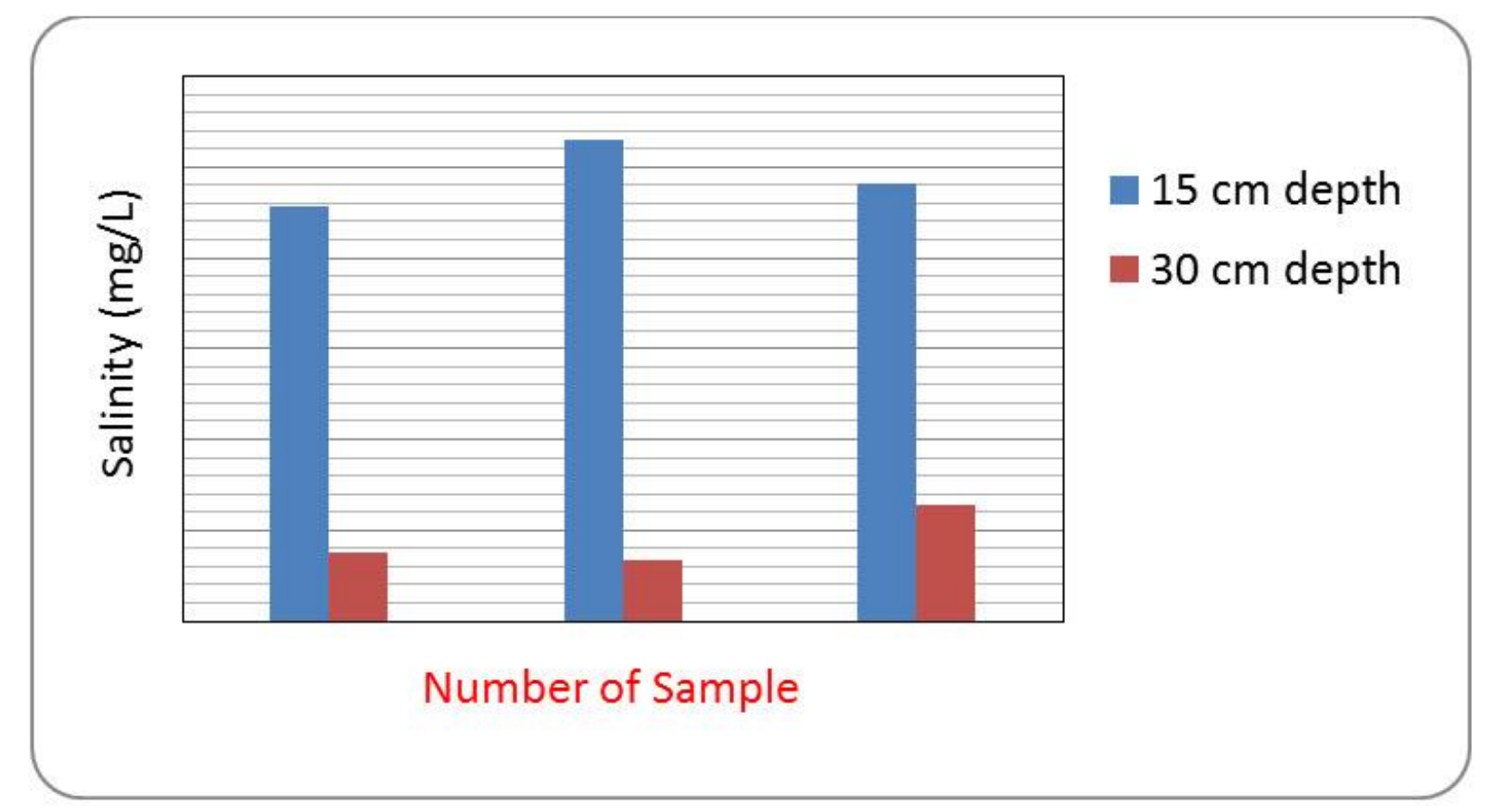

Fig. 12. Variation of Salinity with depth of soil for Gher-F.

Figure 11 shows the salinity is higher at $30 \mathrm{~cm}$ depth than $15 \mathrm{~cm}$ depth for Gher E. Similarly for Gher $\mathrm{D}$ in Fig. 12, salinity is higher at $30 \mathrm{~cm}$ depth than $15 \mathrm{~cm}$ depth at point 1 and 3 for Gher F. Figure 13 depicts that the organic content is higher at $15 \mathrm{~cm}$ depth than as that of $30 \mathrm{~cm}$ depth. However, in Fig. 14, the value of organic content is higher at $30 \mathrm{~cm}$ depth than $15 \mathrm{~cm}$ depth. Gher-E is Agricultural land and $\mathrm{F}$ is combined Agricultural land and Shrimp Gher. 

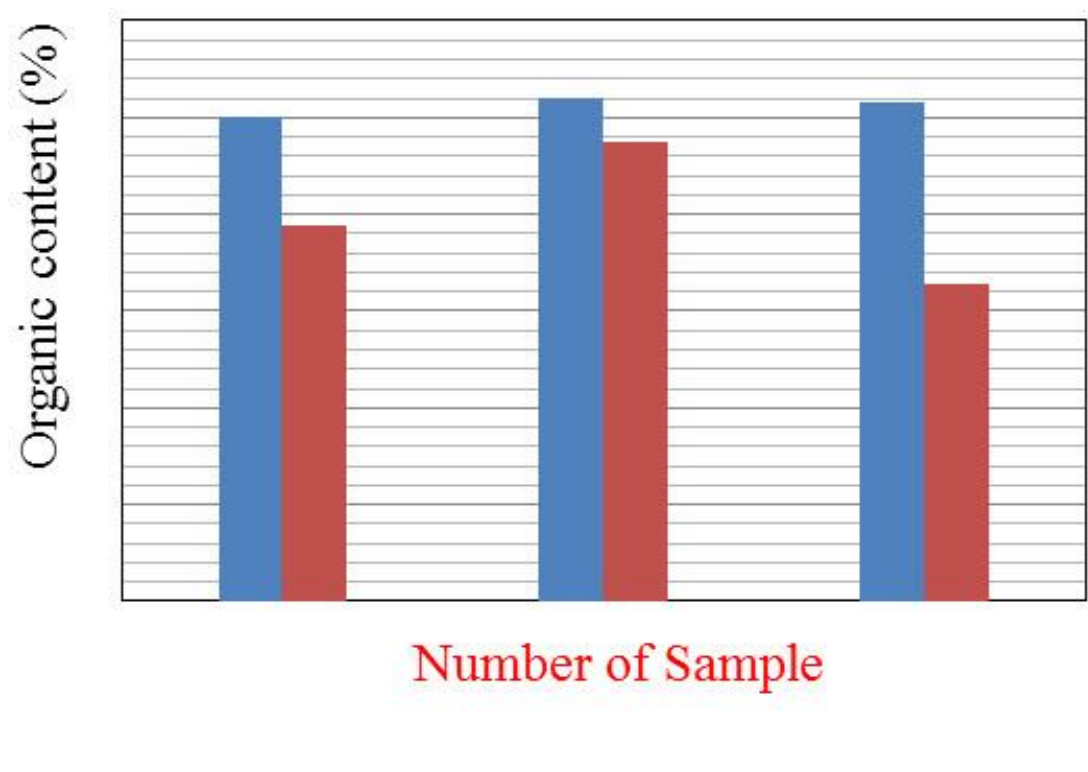

$15 \mathrm{~cm}$ depth $30 \mathrm{~cm}$ depth

Number of Sample

Fig. 13. Variation of Organic content with depth of soil for Gher-E.

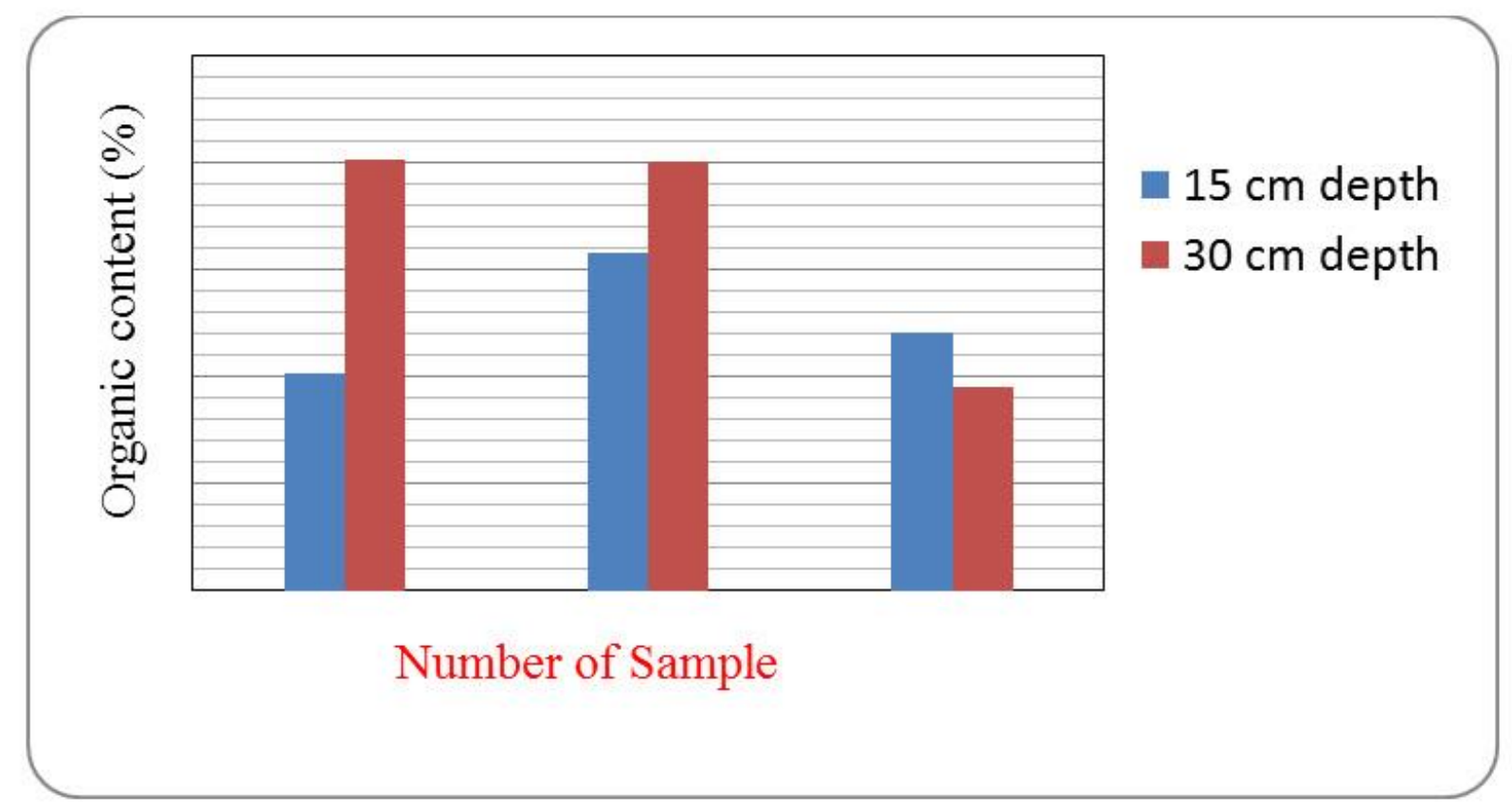

Fig. 14. Variation of Organic content with depth of soil for Gher-F. 


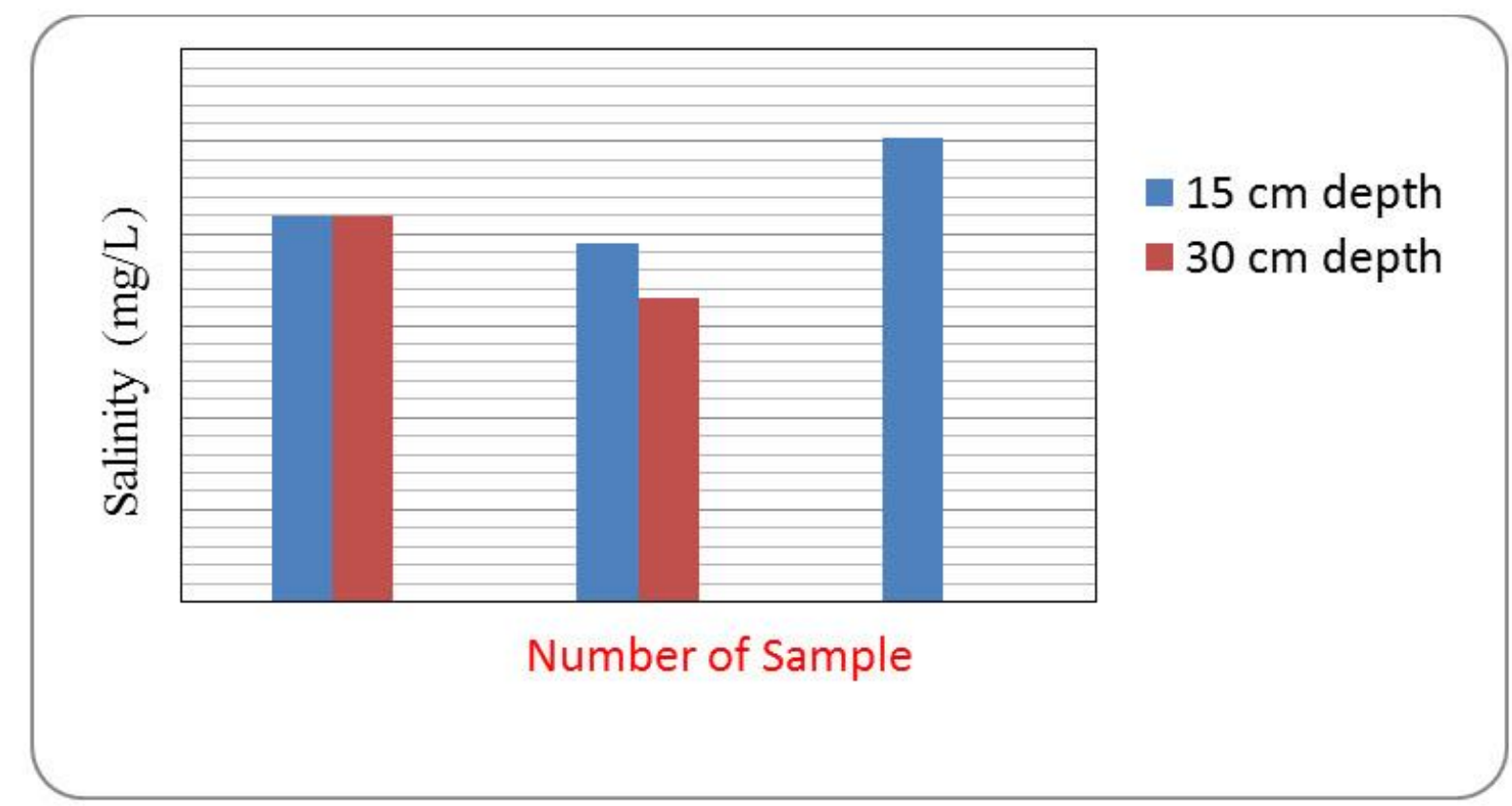

Fig. 15. Variation of Salinity with depth of soil for Gher-G.

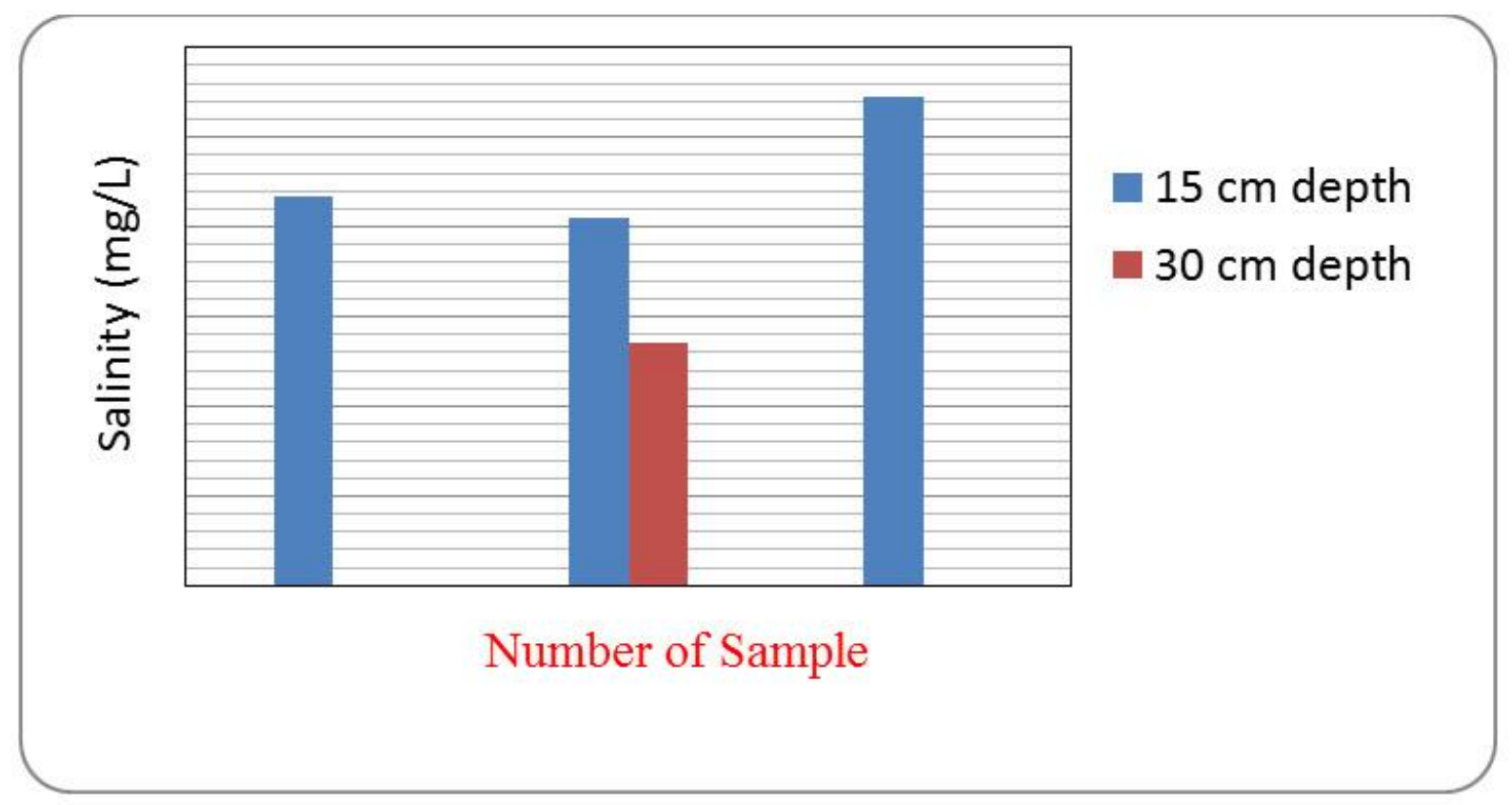

Fig. 16. Variation of Salinity with depth of soil for Gher-H. 


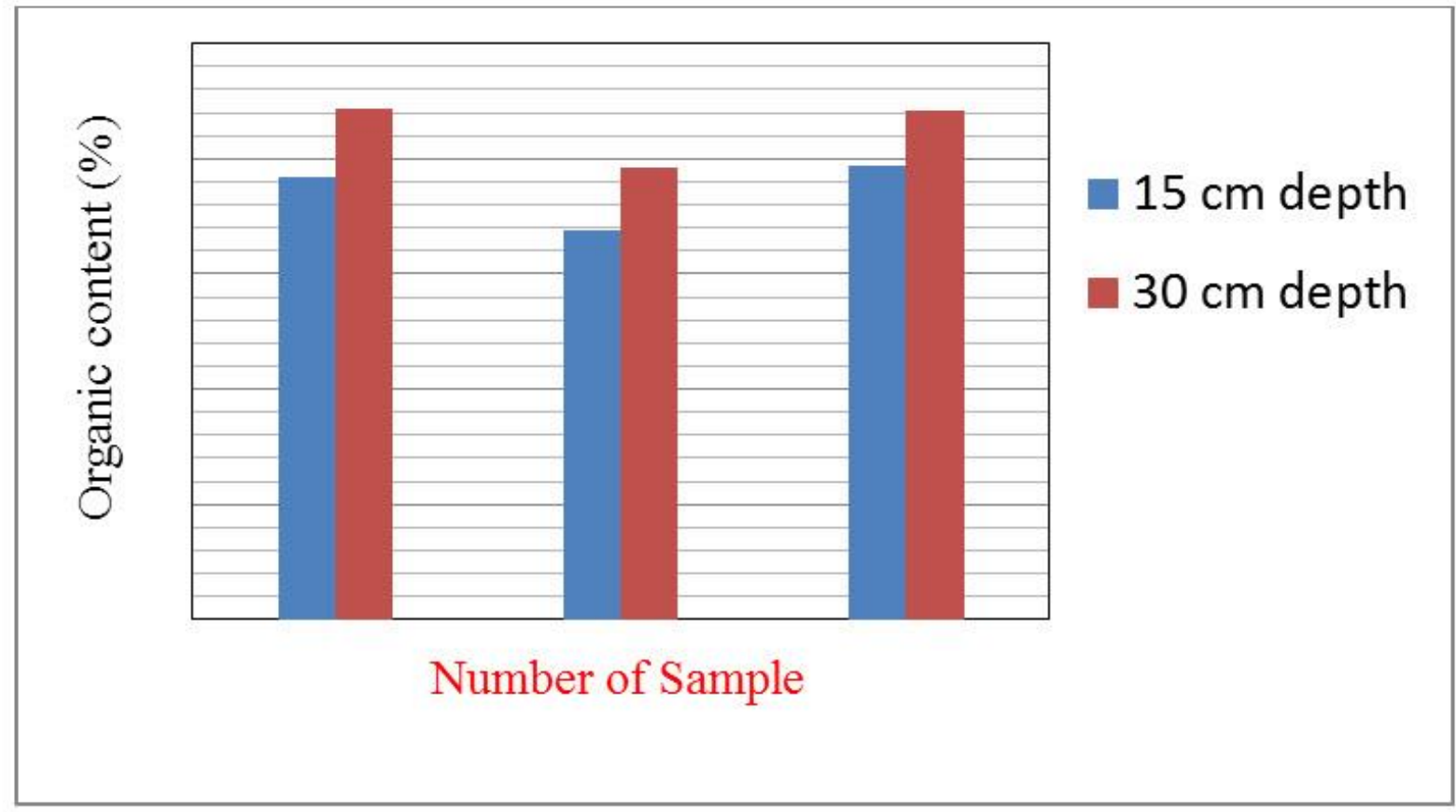

Fig. 17. Variation of Organic content with depth of soil for Gher-G.

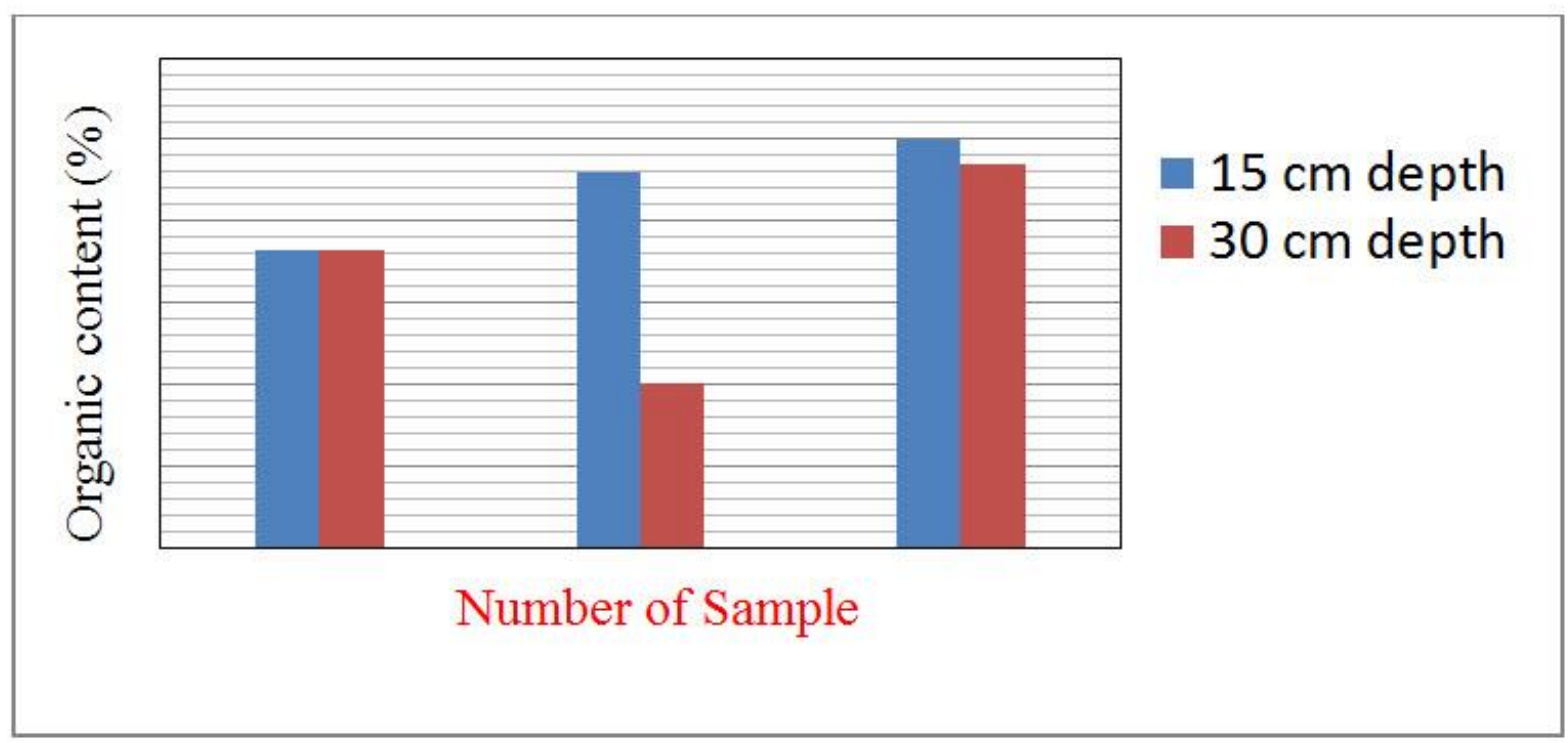

Fig. 18. Variation of Organic content with depth of soil for Gher-H.

From Fig. 15, it is revealed that there is a small difference in salinity between $15 \mathrm{~cm}$ and $30 \mathrm{~cm}$ depth. In Fig. 16, the values of salinity are nil for points 1 and 3. In Fig. 17, it is found that organic content is higher at $30 \mathrm{~cm}$ than $15 \mathrm{~cm}$ depth. However from Fig. 18, it is observed that organic content is same for point 1 in Gher $\mathrm{H}$, however, at points 2 and 3, the value of organic content is higher at $15 \mathrm{~cm}$ depth than $30 \mathrm{~cm}$ depth.

\section{Conclusions}

This is an environmental concern that the salinity is increasing at an alarming rate in areas vicinity to shrimp Ghers. This study was conducted to observe the current status of the native soil at shrimp Gher and agricultural land by characterizing the soil properties. Organic content was found higher at the depth of 30 $\mathrm{cm}$ than that of $15 \mathrm{~cm}$ depth for Gher-A (20 years old) and agricultural land-B. Organic content was lower 
at the depth of $30 \mathrm{~cm}$ than that of $15 \mathrm{~cm}$ depth for Gher-C (5 years old) and Gher-D (13 years old). Organic content was lower at the depth of $30 \mathrm{~cm}$ than that of $15 \mathrm{~cm}$ depth Gher-E (plain agricultural land), located at Dumuria. Organic content was higher at the depth of $15 \mathrm{~cm}$ than that of $30 \mathrm{~cm}$ depth for combined Gher and agricultural land-F (10 years), located at west part of Teligati. Salinity was higher at 15 $\mathrm{cm}$ depth than $30 \mathrm{~cm}$ depth for Gher-A (20 years old), located at Dumuria. Organic content was higher at $30 \mathrm{~cm}$ depth than $15 \mathrm{~cm}$ depth for Gher-G (8 years old), located beside the by-pass road. Salinity was higher at $30 \mathrm{~cm}$ depth than $15 \mathrm{~cm}$ depth for Gher-C (5 years old). Salinity was higher at $30 \mathrm{~cm}$ depth than $15 \mathrm{~cm}$ depth for Gher-D (13 years old). Organic content was higher at $15 \mathrm{~cm}$ depth than $30 \mathrm{~cm}$ for combined Gher-H (5 years old), located beside the by-pass road. Salinity is higher at $15 \mathrm{~cm}$ depth than 30 $\mathrm{cm}$ depth for agricultural land-B. Salinity was higher at $30 \mathrm{~cm}$ depth than $15 \mathrm{~cm}$ depth for agricultural landE. Chloride and conductivity were higher in old Gher and $\mathrm{pH}$ was higher in the new Gher. Salinity was higher at $30 \mathrm{~cm}$ depth than $15 \mathrm{~cm}$ depth for combined shrimp Gher and agricultural land-F (10 years old), located beside the by-pass road. Salinity is a crucial land degradation issue. It can be reduced by leaching soluble salts out of soil with excess irrigation water. Salt-tolerant plants can be planted in areas of high levels of soil salinity.

\section{Acknowledgement}

Authors acknowledge the support provided by UPM (9478700; GP-IPS/2016/9478700)

\section{References}

[1] S. N. Alam, B. Pokrant, A. Yakupitiyage, and M. J. Phillips, "Economic returns of disease-affected extensive shrimp farming in southwest Bangladesh," Aquaculture International, vol. 15, no. 5, pp. 363370, 2007.

[2] Acqua International. (2014). Acqua International info. [Online]. Available: http://acqua-int.com [Accessed: May 10, 2014].

[3] S. M. N. Alam and M. J. Phillips, "Coastal shrimp aquaculture systems in Southwestern Bangladesh," Asian Fisheries Science, vol. 17, pp. 175-189, 2004.

[4] A. M. S. Ali, "Rice to shrimp: land use/land cover changes and soil degradation in Southwestern Bangladesh," Land Use Policy, vol. 23, no. 4, pp. 421-435, 2006.

[5] S. M. Anwar. (2003). Effect of shrimp culture on ecology in the coastal areas of Bangladesh. Human Landscape Ecology. [Online]. pp. 65-76. Available: http://www.sma bd.com/documents/Effect $\% 20$ of $\% 20$ Shrimp $\% 20$ culture.PDF [Accessed: May 10, 2014].

[6] Ministry of Finance, Finance Division, Economic Adviser's Wing, "BER info," Bangladesh Economic Review (BER) 2007-2010, Bangladesh, 2010.

[7] M. A. Chowdhury, G. P. Shivakoti, and M. Salequzzaman, "A conceptual framework for the sustainability assessment procedures of the shrimp aquaculture industry in coastal Bangladesh," International journal of agricultural resources, governance and ecology, vol. 5, no. 2, pp. 162-184, 2006.

[8] A. K. Deb "Fake blue revolution: Environmental and socio-economic impacts of shrimp culture in the coastal areas of Bangladesh,” Ocean \& Coastal Management, vol. 41, no. 1, pp. 63-88, 1998.

[9] I. J. Eva "Economic and ecological assessment of shrimp farming: A study in Debhata Upazila, Satkhira District, Bangladesh," M.Sc. thesis, Department of Geography and Environment, University of Dhaka, pp. 1-68, 2012.

[10] Daily Star. (Feb. 28, 2005). Salinity increasing in SW districts alarmingly. The Daily Star. [Online]. Available: http://archive.thedailystar.net/2005/02/28/d50228070474.htm

[11] A. E. Haque, M. F. D. Arif, S. M. Khan, and A. M. Khan, "Sanitary and phyto-sanitary barriers to trade and its impact on the environment: The case of shrimp farming in Bangladesh," IUCN-The World Conservation Union, Bangladesh Country Office, 2004.

[12] A. A. Islam and M. M. Rahman, "Determination of organic content in different boreholes in Khulna city," B.Sc. thesis, Department of Civil Engineering, KUET, Khulna, Bangladesh, 2008.

[13] M. S. Islam. "From pond to plate: Towards a twin-driven commodity chain in Bangladesh shrimp aquaculture," Food Policy, vol. 33, no. 3, pp. 209-223, 2008. 
[14] M. S. Islam, A. Milstein, M. A. Wahab, A. H. M. Kamal, and S. Dewan, "Production and economic return of shrimp aquaculture in coastal ponds of different sizes and with different management regimes," Aquaculture International, vol. 13, no. 6, pp. 489-500, 2005.

[15] M. S. Islam and M. Haque, "The mangrove-based coastal and nearshore fisheries of Bangladesh: ecology, exploitation and management," Reviews in Fish Biology and Fisheries, vol. 14, no. 2, pp. 153-180, 2004.

[16] S. Hossain, S. M. N. Alam, C. K. Lin, H. A. Demaine, Y. S. Khan, N. G. Das, and M. A. Rour, "Integrated management approach for shrimp culture development in the coastal environment of Bangladesh," World Aquaculture-Baton Rouge, pp. 35-44, 2004.

[17] A.W. Mantyla, "Standard seawater comparisons updated," J. Phys. Ocean., vol. 17, pp. 543-548, 1987.

[18] J. H. Primavera, "Socio-economic impacts of shrimp culture," Aquaculture research, vol. 28, no. 10, pp. 815-827, 1997.

[19] B. G. Paul and C. R. Vogl, "Impacts of shrimp farming in Bangladesh: Challenges and alternatives," Ocean \& Coastal Management, vol. 54, no. 3, pp. 201-211, 2011.

[20] M. A. Salam, L. G. Ross, and C. M. Beveridge, "A comparison of development opportunities for crab and shrimp aquaculture in southwestern Bangladesh, using GIS modeling," Aquaculture, vol. 220, no. 1, pp. 477-494, 2003.

[21] SHAB, "SHAB info," Shrimp Hatchery Association of Bangladesh (SHAB), Bangladesh, 2010.

[22] P. Vossen, "Changing pH in soil," University of California Cooperative Extension, Santa Rosa, USA, $11,2006$.

[23] USAID, Development and Training Services. (2014). USAID Info: A pro-poor analysis of the shrimp sector in Bangladesh. [Online]. Available: http://www.usaid.gov.com [Accessed: May 10, 2014].

[24] M. A. Wahab, A. Bergheim, and B. Braaten, "Water quality and partial mass budget in extensive shrimp ponds in Bangladesh," Aquaculture, vol. 218, no. 1, pp. 413-423, 2003. 